\title{
Artificial selection shifts flowering phenology and other correlated traits in an autotetraploid herb
}

\author{
KS Burgess, JR Etterson ${ }^{1}$ and LF Galloway \\ Department of Biology, University of Virginia, Charlottesville, VA, USA
}

\begin{abstract}
There is mounting evidence that plants are responding to anthropogenic climate change with shifts in flowering phenologies. We conducted a three-generation artificial selection experiment on flowering time in Campanulastrum americanum, an autotetraploid herb, to determine the potential for adaptive evolution of this trait as well as possible costs associated with enhanced or delayed flowering. Divergent selection for earlier and later flowering resulted in a 25-day difference in flowering time. Experiment-wide heritability was 0.31 and 0.23 for the initiation of flowering
\end{abstract}

in early and late lines, respectively. Selection for earlier flowering resulted in significant correlated responses in other traits including smaller size, fewer branches, smaller floral displays, longer fruit maturation times, fewer seeds per fruit and slower seed germination. Results suggest that although flowering time shows the potential to adapt to a changing climate, phenological shifts may be associated with reduced plant fitness possibly hindering evolutionary change.

Heredity (2007) 99, 641-648; doi:10.1038/sj.hdy.6801043; published online 1 August 2007

Keywords: artificial selection; autopolyploid; realized heritability; Campanulastrum americanum; correlated response; flowering time

\section{Introduction}

Phenological shifts that correspond with recent anthropogenic climate change are being observed in many plant and animal species. For example, initiation of flowering 3-8 days earlier has been documented by recent studies (Bradley et al., 1999; Fitter and Fitter, 2002; Primack et al., 2004). However, it is rarely known whether these phenological changes represent evolutionary change or a plastic response to a warming climate (Bradshaw and Holzapfel, 2006; Réale et al., 2003). This is in part determined by the magnitude of additive genetic variation for phenological traits or the expression of genetic variation in the plastic response to the environment of these traits. Life history traits, such as age of first reproduction (initiation of flowering), typically have lower heritability than those traits with a weaker covariance with fitness (Crnokrak and Roff, 1995; although not necessarily due to reduced additive genetic variance, Houle, 1992). It seems likely that adaptive evolution of plants and hence persistence in a warming climate will depend on the magnitude of additive genetic variation for targets of selection such as flowering time.

Genetic interactions between traits under selection and correlated traits were first postulated by Darwin (1859) and have been described in numerous plant and animal systems since (Roff, 1997; Conner and Hartl, 2004). For

Correspondence: Dr KS Burgess, Department of Ecology and Evolutionary Biology, University of Toronto, 25 Wilcocks Street, Toronto, Ontario, Canada M5S 3B2.

E-mail: kburgess@eeb.utoronto.ca

${ }^{1}$ Current address: Department of Biology, University of Minnesota, Duluth, MN, USA.

Received 21 November 2006; revised 10 June 2007; accepted 3 July 2007; published online 1 August 2007 example, selection for larger pollen results in a correlated response of larger flowers (Sarkissian and Harder, 2001), and selection for larger flower size results in a decreased floral display size (Delph et al., 2004). An understanding of the shared genetic basis of traits is important because while greater additive genetic variation and heritability enhance the potential for evolutionary response, genetic correlations may either facilitate or hinder evolutionary change depending upon whether correlated responses also increase fitness (Etterson and Shaw, 2001; Etterson, 2004). In particular, life history traits such as timing of flowering are often genetically correlated and closely associated with fitness. We know little about selection response and the possible costs associated with enhanced or delayed flowering phenotypes.

The autotetraploid herb Campanulastrum americanum exhibits natural variation in flowering time within and among populations. In this outcrossing, insect-pollinated species genetically based earlier flowering phenotypes are found at lower elevations (Galloway et al., 2003) and lower latitudes (Kalisz and Wardle, 1994). When plants from high elevation populations were planted in a low elevation site, simulating a warmer climate, phenotypic selection favored earlier flowering (Haggerty, 2006). Across latitudes, early flowering is associated with smaller overall size and reduced reproductive output (Kalisz and Wardle, 1994). Therefore, changes in flowering time may be associated with changes in plant fitness. However, it is not known whether these changes represent independent evolution of traits in response to local environmental conditions or correlated responses to selection for earlier flowering. At lower elevations and latitudes, early flowering is associated with earlier timing of germination. If timing of fruit maturation, another phenological trait, is also shorter in early 
flowering plants, it could have substantial effects on fitness in $C$. americanum where fall-germinating seeds grow as annuals and spring-germinating seeds are biennials (Baskin and Baskin, 1984). Therefore selection for earlier flowering by a warmer climate could result in correlated response that alters the species life history schedule.

Artificial selection is a direct and powerful way to test the potential for evolution of specific traits, such as flowering time, that may be targets of selection. It has been used to elucidate patterns of heritability for numerous traits (Falconer and Mackay, 1996; Roff, 1997; Brakefield, 2003; Conner, 2003; Fry, 2003) and their correlated responses (Worley and Barrett, 2000; Sarkissian and Harder, 2001; Geber and Griffen, 2003; Delph et al., 2004). However, response to selection in C. americanum may differ from these studies because it is an autotetraploid. Autopolyploids are expected to harbor greater genetic diversity than diploids, which may enhance response to selection (reviewed in Otto and Whitton, 2000). Also, as a result of tetrasomic inheritance where two alleles are inherited per locus, both additive and dominance variation may contribute to selection response (Wricke and Weber, 1986). A larger portion of the total genetic variance contributing to selection response may enhance response to selection in autotetraploids relative to diploids. Despite their prevalence (Masterson, 1994; Soltis and Soltis, 2003), there are few studies of response to selection in natural autopolyploid plants.

To increase our understanding of the potential for evolution of flowering phenology, we conducted three generations of artificial selection in C. americanum. Specifically, we evaluated the direct response to selection for early and late flowering time and correlated responses in other phenological and morphological traits.

\section{Materials and methods}

\section{Artificial selection}

Two base populations were established for artificial selection by collecting $\sim 200$ maternal seed families of C. americanum Small (formally Campanula americana L.) from a naturally occurring population near the Mountain Lake Biological Station, Giles County, Virginia, USA (elevation: $1233 \mathrm{~m}$ ). Individuals in this population grow on a hillside under the deciduous forest canopy as well as in tree-fall light gaps; fairly typical habitat for this species (Galloway, 2005). Two seeds per family were germinated in a growth chamber in a randomized design $\left(21^{\circ} \mathrm{C}\right.$ day $/ 12^{\circ} \mathrm{C}$ night, $12 \mathrm{~h}$ days). Following 49 days of germination, the temperature was reduced to $5^{\circ} \mathrm{C}$ and seedlings were vernalized for 42 days to stimulate flowering. After vernalization, one seedling per family was transplanted to $4 \times 14 \mathrm{~cm}$ tubular pots containing a 3:1 mixture of Promix BX and Turface and moved to the University of Virginia greenhouses. Plants were arranged into four blocks, watered and fertilized as necessary, and reared under supplemental lighting (16-h days). The baseline generation $\left(G_{0}\right)$ for each of the two replicate populations was composed of 100 randomly assigned plants.
Artificial selection on flowering time was based on the number of days from the end of the vernalization treatment to first flower. For each base population, the earliest flowering 20\% (E), the latest flowering 20\% (L) and a random control group 20\% (C) were used to produce six selection lines: one upward, one downward and one control per replicate. The control group was chosen from across the flowering range; therefore it was possible for an individual to be a member of the control group and the early or late flowering group. To produce the $G_{1}$ generation, each plant was crossed to three other members of its selected group acting either as a male (pollen donor) in two crosses and a female (pollen recipient) in one cross or as a male once and a female twice. This design resulted in 30 families per selection line (see Worley and Barrett, 2000 for a similar design). Because $C$. americanum is self-compatible and protandrous, flowers used as pollen recipients were emasculated while in the male phase. Replicate crosses were done on three flowers. Fruits were harvested when ripe and seeds stored at $4{ }^{\circ} \mathrm{C}$.

To produce the $G_{2}$ and $G_{3}$ generations, six seeds from each of the 30 families in each selection line were germinated as described above (1080 seeds total). After vernalization, 100 plants per line were transplanted and grown in the greenhouse (600 plants total). For each selection line these included three seedlings from 20 randomly chosen families and four seedlings from the remaining 10 families. Due to poor seed production, there were fewer than 30 families in some lines and therefore a greater number of seedlings of each family were used to contribute to the 100 plants grown for that line. The selection criteria and crossing design were the same as for $G_{1}$, with the earliest flowering $20 \%$, the latest flowering $20 \%$ and a random $20 \%$ selected for crossing in the early, late and control lines, respectively. Siblings within a family had similar flowering times and therefore the early and late selected groups within each generation often included several siblings. To maintain similar levels of relatedness among lines, the number of siblings for the control lines in each generation was adjusted to approximate those of early and late flowering lines. For example, in the final generation of selection 16 random families contributed to the 20 plants in each control line with 4 of the families represented by 2 siblings. This approximated the contribution of siblings to the early and late lines. Crosses between known relatives were avoided to minimize inbreeding.

\section{Evaluating response to selection}

Direct response to selection on flowering time and correlated response on other phenological and morphological traits were measured following three generations of artificial selection. Eight $\mathrm{G}_{3}$ seeds from 28 families in C1, E1 and E2, and 30 families in C2, L1 and L2 were individually weighed and germinated in the growth chamber in a fully randomized design under the conditions described above (1392 total). Germination was scored as the number of days from planting to cotyledon emergence. After vernalization, 600 plants (100 per selection line) were transplanted and grown in a randomized block design following the procedures described above. The date of first flower was recorded and flower size was assessed as the average width of two 
flowers produced within the first five days of flowering. To determine the timing of fruit maturation and seeds per fruit, two flowers were emasculated and hand pollinated with pollen pooled from $\sim 10$ randomly selected individuals within the same selection line. These fruits were harvested when mature (straw colored; a day or two before dehiscing) and the seeds counted. Floral display size, the number of open flowers, was evaluated when the plants were relatively young (10 days after the first flower opened) and old (when the first fruit of the pollinated flowers matured). Plants were harvested on the day of fruit maturation and weighed when dry. Basal branches (that is, those from the rosette) and the main stem were harvested and weighed separately. Biomass allocated to branches was calculated as a proportion of total biomass.

\section{Data analysis}

Interannual environmental variation may affect flowering time and influence heritability estimates. To remove these environmental effects, flowering time was adjusted by subtracting the mean flowering time of the control lines for a specific generation from each individual's trait value in that generation (Falconer and Mackay, 1996; Delph et al., 2004). The average of the two control lines was used because environmental effects are expected to influence both lines similarly and pooling the two lines provided a more robust sample of annual effects.

The selection differential $(S)$ and response to selection $(R)$ were determined after each round of selection using the adjusted trait values. $S$ was the difference between the mean flowering time of the 20 selected individuals and the mean of the line from which they were selected. Selection differentials were weighted by the proportional contributions of parents to the next generation to account for unequal representation among families within each selection line (Falconer and Mackay, 1996, p 196). $R$ was calculated by subtracting the mean of the current generation from the mean of the previous generation within each line. For each generation we calculated realized heritability $\left(h^{2}\right)$ of flowering time as $R / S$. Standard errors for each estimate of $h^{2}$ were calculated to account for variance that may be due to genetic drift as:

$$
\operatorname{Var}\left(h^{2}\right) \approx V_{\mathrm{p}} / S^{2}\left[\left(h^{2} / N\right)+(2 / M)\right]
$$

where $V_{\mathrm{p}}$ represents the phenotypic variance within a given generation, $M$ the number of plants measured within that generation and $N$ the number of plants selected to act as parents for the next generation (Roff, 1997, p 137). If $h^{2}$ estimates were negative, zero was substituted into the equation for $h^{2}$ (Roff, 1997, p 137).

The experiment-wide realized heritability that incorporates all three generations of selection was also estimated for each selection line. The cumulative selection differential was calculated for each generation as the sum of $S$ from the first generation of selection through the current generation. Similarly, the cumulative $R$ was calculated for each generation as the change in flowering time between the current generation and the base population. For each selection line the experiment-wide realized heritability for flowering time was estimated as the slope of the line when the cumulative $R$ was regressed against the cumulative $S$ (Falconer and Mackay, 1996, pp 197-198; Roff, 1997, pp 137-141).

The direct response to selection on flowering time in the third generation was evaluated using analysis of variance (ANOVA) with selection line and block (as a random effect) as the sources of variation. Independent contrasts were performed to test for differences in flowering time across the six selection lines between the three pairwise combinations of early, late and control selection regimes. Values for flowering time were log transformed before analysis.

Correlated responses to selection were evaluated for each of the phenological and morphological traits measured in $G_{3}$. As with the timing of flowering, ANOVA was conducted with selection line and block (random) as the sources of variation and independent contrasts were used to identify differentiation between selection regimes for each response variable. Because plant size varied among the selection regimes, biomass was included as a covariate in the ANOVA model for all floral and fruit traits to determine whether any correlated responses to selection were simply due to differences in size. To meet the assumptions of normality, seed weight, germination time and floral display size were squareroot transformed. Fruit maturation time and total above-ground biomass were log transformed and the proportion of biomass allocated to branches was arcsinesquare-root transformed. All statistical analyses were conducted using JMP statistical software (SAS Institute, 2002).

\section{Results}

Flowering time differed significantly among the selection regimes following three generations of selection (Table 1). Early lines flowered 25.4 days earlier on average than late lines, while control lines were intermediate $\left(\bar{x}_{\mathrm{E}}=77.1 ; \bar{x}_{\mathrm{C}}=90.4 ; \bar{x}_{\mathrm{L}}=102.4 ;\right.$ Figure 1$)$. Relative to the controls, early lines flowered 13.3 days earlier $(14.7 \%)$ and the late lines flowered 12 days later (13.3\%).

Realized heritabilities for flowering time estimated for the early selection lines were generally high (overall $\bar{x}=0.30$; s.e. 0.04 ), with the exception of the last E2

Table 1 Direct and correlated responses to selection on flowering time in C. americanum after three generations of artificial selection. F statistics are shown for ANOVA that compare the means of early flowering (E), control (C) and late flowering (L) selection lines for phenological and morphological traits (d.f. $=5,>560)$. Test statistics for independent contrasts compare control vs early (C-E), control vs late $(\mathrm{C}-\mathrm{L})$ and early vs late (E-L) over replicate lines; d.f. $=1,>560$

\begin{tabular}{lcccc}
\hline Response variable & $F$ & $C-E$ & $C-L$ & $E-L$ \\
\hline Flowering time & $126.05^{* * *}$ & $186.02^{* * *}$ & $127.69^{* * *}$ & $612.32^{* * *}$ \\
Seed mass & $13.77^{* * *}$ & 2.25 & 1.35 & $7.08^{* *}$ \\
Germination time & $3.52^{* *}$ & $8.88^{* *}$ & $4.12^{*}$ & 0.85 \\
Young display & $14.18^{* * *}$ & $67.24^{* * *}$ & $7.20^{* *}$ & $27.93^{* * *}$ \\
Old display & $15.25^{* * *}$ & $34.20^{* * *}$ & 1.52 & $48.57^{* * *}$ \\
Flower size & $3.20^{* *}$ & 2.22 & $5.86^{*}$ & $15.21^{* * *}$ \\
No. of seeds /fruit & $13.33^{* * *}$ & $27.56^{* * *}$ & 0.92 & $17.64^{* * *}$ \\
Fruit maturation time & $15.86^{* * *}$ & $64.32^{* * *}$ & $6.92^{* *}$ & $27.56^{* * *}$ \\
Biomass & $83.71^{* * *}$ & $137.36^{* * *}$ & $72.93^{* * *}$ & $407.64^{* * *}$ \\
Branch allocation & $12.35^{* * *}$ & $22.56^{* * *}$ & $6.00^{*}$ & $51.41^{* * *}$
\end{tabular}

${ }^{*} P<0.05$.

$* * P<0.01$

$* * * P<0.001$ 


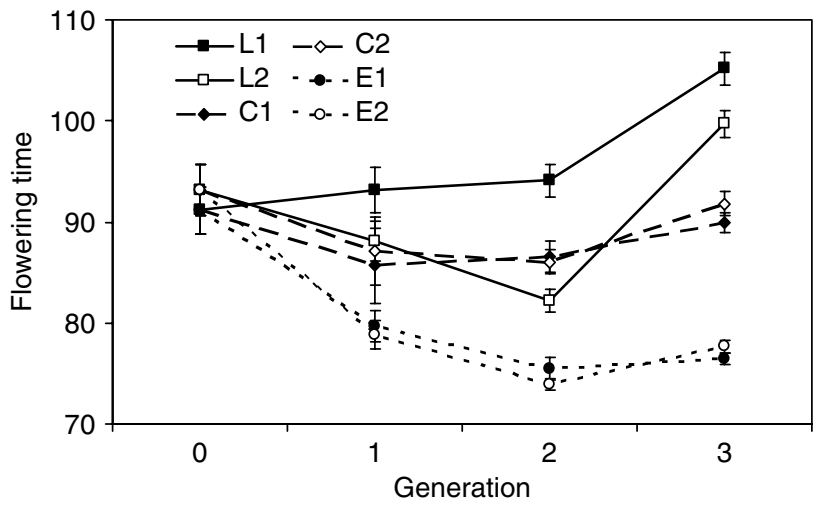

Figure 1 The mean number of days to flower for $C$. americanum following three generations of artificial selection for early flowering (E1 and E2), late flowering (L1 and L2) and a random flowering control (C1 and C2).

Table 2 Realized $h^{2}$ (s.e.) for each of three generations of selection on flowering time in C. americanum

\begin{tabular}{lcccr}
\hline Generation & $E 1$ & $E 2$ & L1 & \multicolumn{1}{c}{ L2 } \\
\hline $\mathrm{G}_{0}$ & $0.29(0.04)$ & $0.41(0.05)$ & $0.21(0.02)$ & $-0.004(0.01)$ \\
$\mathrm{G}_{1}$ & $0.31(0.04)$ & $0.38(0.04)$ & $0.05(0.04)$ & $-0.12(0.03)$ \\
$\mathrm{G}_{2}$ & $0.33(0.05)$ & $0.05(0.02)$ & $0.34(0.02)$ & $0.61(0.03)$ \\
\hline \multicolumn{2}{c}{ for two replicate lines selected for early flowering (E1 and E2) } \\
and two replicate lines selected for late flowering (L1 and L2).
\end{tabular}

generation (Table 2). In contrast, heritabilities estimated for the late lines were more variable ranging from 0.05 to 0.34 in L1 and from -0.12 to 0.61 in L2 (Table 2). Overall, the mean estimate for the late lines $(\bar{x}=0.18$; s.e. 0.03$)$ was substantially lower than for the early lines. Heritability estimates smaller than 0.05 are approximately equal to zero when s.e. are taken into account. In these cases flowering time changed little from one generation to the next. Experiment-wide heritability estimates, incorporating total response to three generations of selection on flowering time, similarly found that early lines had higher realized heritability $(\bar{x}=0.31)$ on average than late lines $(\bar{x}=0.23$; Figure 2$)$.

Correlated responses to artificial selection on flowering time were pronounced for plant size traits. The aboveground biomass of plants in the early flowering selection lines was $29 \%$ smaller and the late flowering lines $26 \%$ larger than plants in the control lines (Figure 3, Table 1). This difference in size is attributable in part to correlated responses to selection in branchiness; early flowering lines had significantly reduced allocation to branches whereas late flowering lines had significantly greater allocation to branches (Figure 3, Table 1).

For floral traits, correlated responses to selection also differed between the early and late selection lines. For example, the flowers of the late selection lines were significantly larger than the early lines, but early lines did not differ from the controls (Figure 3, Table 1). Similarly, early lines had smaller floral displays than late lines for both young and older age plants (Figure 3, Table 1). However, control lines had larger floral displays than both selection regimes for young plants, but did not differ from the late flowering lines in older individuals.

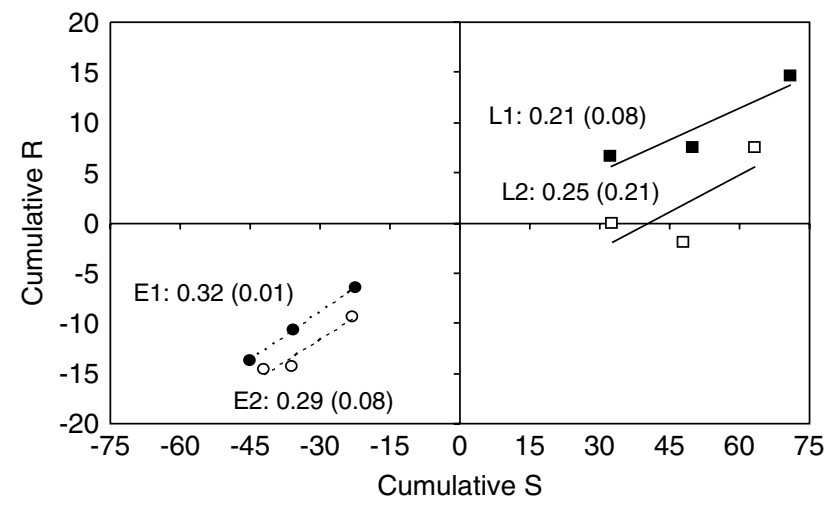

Figure 2 Experiment-wide realized heritability (s.e.) after three generations of artificial selection for early and late flowering in $C$. americanum. $h^{2}$ for each replicate early (E1 and E2) and late (L1 and L2) selection lines was calculated as the slope of the regression line for the cumulative response to selection $(R)$ vs the cumulative selection differential $(S)$ and is indicated next to the fitted line; all slopes were significant at $P<0.05$.

For young plants, the differences in display size between early and late flowering lines were attributable to plant size; when biomass was included as a covariate the contrast was no longer significant $\left(\mathrm{E}\right.$ vs $\mathrm{L} \mathrm{F}_{1546}=0.42$, $P>0.5$ ). However, biomass did not explain the larger display size for older late flowering plants.

Both early and late selection lines took significantly more time to mature their fruit than the control lines (Figure 3, Table 1). Early lines also took longer to mature fruit than the late lines. Furthermore, early lines had fewer seeds per fruit than both control and late flowering lines, and greater seed mass than late flowering lines (Figure 3). The correlated response to selection was less consistent for seeds per fruit and seed weight than other traits measured (Figure 3). Germination time was significantly slower in both early and late selection lines compared to the controls (Figure 3).

\section{Discussion}

Divergent artificial selection for early and late flowering in this C. americanum population differentiated flowering time by 25 days after only three generations of selection. The experiment-wide heritability that resulted in this differentiation was fairly high with between 23 and $31 \%$ of the variation in flowering time observed in the offspring generation attributable to additive genetic variance in their parents. Although exact heritability estimates are expected to vary with population sampled and environmental conditions, our results correspond to a broad survey of narrow sense heritabilities for flowering time in other wild, outcrossing plant species (mean $h^{2}=0.38$, s.e. 0.06; Geber and Griffen, 2003). For example, heritability estimates for flowering time are between 0.10 and 0.49 in Raphanus sativus (Mazer and Schick, 1991), 0.33 in Beta vulgaris ssp maritima (Van Dijk et al., 1997) and 0.23 in Silene nutans (Hauser and Weidema, 2000).

Realized heritability estimates for flowering time in $C$. americanum may be influenced by the fact that the species is an autotetraploid. The production of gametes with two alleles at each locus results in the inheritance of both 

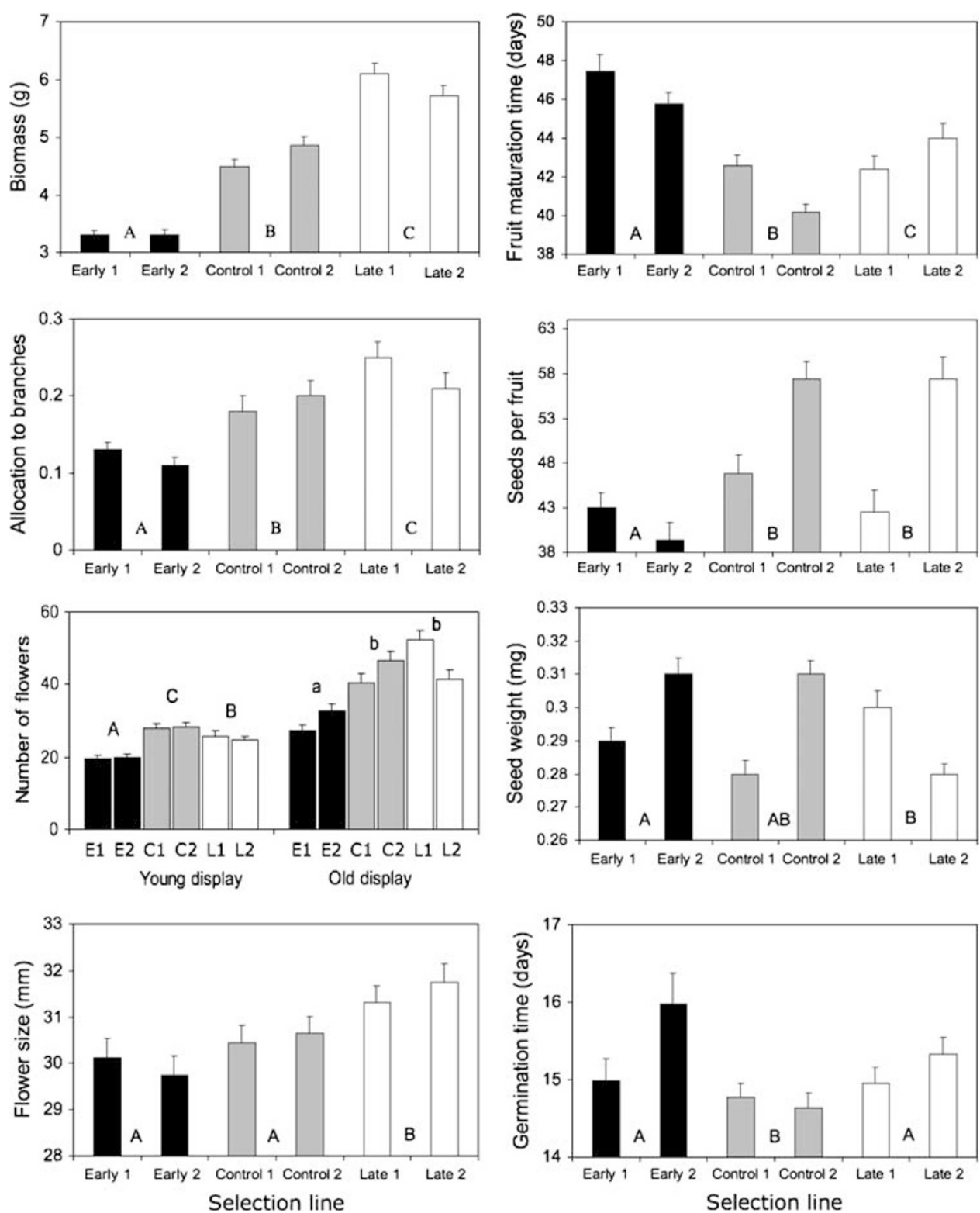

Figure 3 Correlated responses to selection for mean (s.e.) total above-ground biomass, the proportion of biomass allocated to branches, young and old display size, flower size, fruit maturation time, seeds per fruit, seed weight and germination time in C. americanum following three generations of artificial selection for early (E1 and E2), control (C1 and C2) and late (L1 and L2) flowering time. Selection regimes with different letters indicate significance differences based on independent contrast analysis.

additive genetic effects as well as dominance. Therefore, while response to selection in diploids can be predicted by $h^{2} S$, in autotetraploids it is

$$
R=h^{2} S+\left(1 / 3 \sigma^{2} D / \sigma^{2} P\right) S,
$$

where the ratio of the dominance variance to phenotypic variance contributes to selection response as well as the heritability (Wricke and Weber, 1986). As a result, estimates of realized heritability calculated solely on the basis of selection response $(R / S)$ are likely to overestimate the true heritability. The contribution of dominance to selection response will decrease as individuals mate randomly in the generations following selection and diploid models are appropriate to describe selection response after the population has reached equilibrium (Wricke and Weber, 1986). Previous work suggests the contribution of dominance to flowering time in $C$. americanum is limited. Specifically, flowering time was the only trait in $C$. americanum that did not express inbreeding depression in field studies (Galloway and Etterson, 2007) and had the smallest inbreeding depression of all traits measured in the greenhouse $(-0.0065$, Galloway et al., 2003). Because inbreeding depression is due to the expression of deleterious recessive alleles, the lack of inbreeding depression in this single trait suggests that there is little dominance for flowering time. Similarly, flowering time of intraspecific hybrids was typically intermediate to their parents, again suggesting limited dominance (Galloway and Etterson, 2005). With a limited contribution of dominance to flowering time, the realized heritability we measured was likely a close estimate of the true value. 
Heritability estimates of polyploids may exceed those of diploids because of greater levels of genetic diversity as well as the contribution of dominance to heritability. Our heritability estimates for flowering time are within range, and slightly smaller than the mean, of other wild plant species (Geber and Griffen, 2003). Similarly, autotetraploid Lythrum salicaria has heritability estimates similar to other wild plant taxa (although a much smaller heritability for flowering time, $h^{2}=0.093$; O'Neil, 1997). While additional studies are needed in wild autopolyploids to determine the generality of these findings, together they suggest that ploidy level does not substantially alter evolutionary potential and that patterns of selection response of plants which are frequently polyploid will resemble those of animals.

The direct response to three generations of selection on flowering time in $C$. americanum differed between the selection regimes. Flowering time was typically more variable among individuals within the late flowering lines than the early flowering lines. Realized heritability was also more variable between generations in the late flowering lines. In addition, the pattern of variability in the late flowering lines differed between the selection replicates. This greater variation in selection response in the late flowering lines is reflected in the smaller realized heritability for flowering time in the late lines $\left(h^{2}=0.23\right)$ than in the early lines $\left(h^{2}=0.31\right)$. A smaller heritability for flowering time in the late lines may also reflect an underlying asymmetry in the allelic frequencies of the genes determining flowering time. If late flowering alleles are more frequent than alleles for early flowering, there would be a greater response to selection in the early direction (Roff, 1997, p 136). Variable patterns of heritability across generations of selection, and between selection treatments, are quite common in artificial selection experiments (reviewed in Conner and Hartl, 2004). Given such variation in heritability, our results highlight the utility of experiment-wide heritability estimates for predicting long-term selection response.

Lower and more variable heritability estimates for late flowering than early flowering may not be very surprising. The response to selection indicates that plants flower late, in part, due to their genetic composition. However, plants may also flower late if they are weak or developmentally retarded. Plants may be weak for environmental reasons, for example, small-scale variation in the greenhouse climate, variation in soil volume and hence water availability or insect damage. They may also be weak due to genetic reasons not associated with flowering time, for example, aberrant leaf development. In contrast, there are fewer alternate sources of the early flowering phenotype. This difference in the underlying cause of early and late flowering phenotypes is also likely to be found in nature. As a consequence, our results suggest that unique patterns of response to selection for early and late flowering may contribute to differences in the efficiency of evolution in response to natural selection on this trait.

Strong genetic correlations between phenological, morphological and reproductive traits may inhibit evolutionary response to selection in nature. For example, early flowering lines were composed of smaller plants with less branching, smaller floral displays composed of smaller flowers, fewer seeds per fruit and slower fruit maturation and seed germination than the control lines. It is likely that these correlated responses to selection for earlier flowering are in the opposite direction to the phenotypic values favored by selection in nature (Conner and Rush, 1996; Maad and Alexandersson, 2004; Hansen and Totland, 2006). Therefore, trade-offs in the underlying genetic architecture of traits that are the targets of selection may limit evolutionary change for flowering time because the increase in fitness associated with a change in reproductive timing may be countered by maladaptive responses in other fitness components.

The other phenological traits measured, timing of germination and fruit maturation, were the only traits in which the control lines were not intermediate to the early and late flowering selection lines. The control lines germinated and matured fruits more rapidly than either of the selection lines. This result is a bit surprising because phenological traits have been shown to be positively correlated in other species (Rathcke and Lacey, 1985; Kelly, 1992; O'Neil, 1997). However, if flowering time is under stabilizing selection (LF Galloway and KS Burgess, unpublished data), artificial selection away from the phenotypic norm of the population will result in an increased frequency of alleles rarely expressed in natural populations. The longer duration of germination and of fruit maturation in the selection lines may reflect a lack of vigor due to the expression of alleles at correlated traits that have not frequently experienced the rigors of selection. Slower timing of fruit maturation and germination in plants of the early flowering selection lines relative to the controls indicates that the overall phenology is not accelerated. Therefore, changing the time of flowering may not alter whether seeds germinate in the fall as annuals or the spring as biennials. However, field tests are required to confirm this conclusion.

Correlated responses to artificial selection on flowering time resulted in the evolution of suites of life history characters common to other plant taxa. Plants in early flowering selection lines not only flowered earlier but were also smaller with smaller display sizes than those in late flowering lines, a group of traits often found in plants with a shorter lifespan (Olsson and Agren, 2002; Kollmann and Bañuelos, 2004; Griffith and Watson, 2005). Some taxa that share these traits also have smaller flowers and produce fewer seeds per fruit, like the early flowering selection lines (Dole, 1992). There are also similar patterns in C. americanum populations from different habitats. For example, at low elevations and low latitudes C. americanum flower earlier than at higher elevations and higher latitudes (Kalisz and Wardle, 1994; Galloway et al., 2003). Along a local-scale elevation gradient, changes in phenology and morphology are comparable to the early and late flowering phenotypes found in our artificial selection experiment (Haggerty, 2006). The similarity of character combinations that we found resulting from selection, to those of other C. americanum populations and other taxa, suggests selection on a single life trait may result in evolution of a suite of life history characters due to underlying genetic correlations.

The phenological shifts that we produced by artificial selection exceed the 3-8 days that have been documented in response to a warming climate for most wild species (Bradley et al., 1999; Fitter and Fitter, 2002; Primack et al., 2004). There are many unknown factors that may 
influence the extent to which this pattern may be repeated in nature. First, we do not know whether populations would exhibit plastic responses to warming of similar magnitude. Phenotypic plasticity would buffer populations against selection and reduce the evolutionary response. Second, the strength of selection imposed in this experiment likely exceeds that of natural selection on flowering time in the field. However, when $C$. americanum plants were grown in field conditions with an earlier spring, we found phenotypic selection for earlier flowering (Haggerty, 2006). Finally, we do not know the extent to which potentially maladaptive correlated responses to selection, such as smaller plant size and fewer seeds per fruit would retard evolutionary response of early flowering. Nevertheless, this study suggests that it is possible that strong natural selection could rapidly alter the flowering phenology in this native plant species in a direction that is coherent with global change scenarios.

The substantial response to selection and the relatively high heritable component for flowering time of C. americanum indicates that natural selection could result in rapid adaptive response for flowering phenology in this population. However, our study also shows that flowering time will not evolve independently. Strong genetic correlations between morphological, phenological and reproductive traits indicate that selection for earlier or later flowering will result in differentiation for a suite of traits that are also expected to influence fitness. In particular, adaptive evolution of earlier flowering may incur a cost to plant fitness.

\section{Acknowledgements}

We thank V Fuentes, L Guarinello, R Gittman, A Smith and $\mathrm{H}$ Truong for assistance in the greenhouse; W Crannage for plant care; $M$ Geber for sharing a literature summary; NSF (DEB-9974126, DEB-0316298) and a UVA-FEST award to LFG for financial support.

\section{References}

Baskin JM, Baskin CC (1984). The ecological life-cycle of Campanula americana in Northcentral Kentucky. Bull Torrey Bot Club 111: 329-337.

Bradley NL, Leopold AC, Ross J, Huffaker W (1999). Phenological changes reflect climate change in Wisconsin. Proc Natl Acad Sci USA 96: 9701-9704.

Bradshaw WE, Holzapfel CM (2006). Evolutionary response to rapid climate change. Science 312: 1477-1478.

Brakefield PM (2003). Artificial selection and the development of ecologically relevant phenotypes. Ecology 84: 1661-1671.

Conner JK (2003). Artificial selection: a powerful tool for ecologists. Ecology 84: 1650-1660.

Conner JK, Hartl DL (2004). A Primer of Ecological Genetics. Sinauer Associates: Sunderland, MA.

Conner JK, Rush S (1996). Effects of flower size and number on pollinator visitation to wild radish, Raphanus raphanistrum. Oecologia 105: 509-516.

Crnokrak P, Roff DA (1995). Dominance variance: associations with selection and fitness. Heredity 75: 530-540.

Darwin C (1859). The Origin of Species by Means of Natural Selection. Murray: London.

Delph LF, Gehring JL, Frey FM, Arntz AM, Levri M (2004). Genetic constraints on floral evolution in a sexually dimorphic plant revealed by artificial selection. Evolution 58: 1936-1946.
Dole JA (1992). Reproductive assurance mechanisms in 3 taxa of the Mimulus guttatus complex (Scrophulariaceae). Am J Bot 79: 650-659.

Etterson JR, Shaw RG (2001). Constraint to adaptive evolution in response to global warming. Science 294: 151-154.

Etterson JR (2004). Evolutionary potential of Chamaecrista fasciculata in relation to climate change: II. Genetic architecture of three populations reciprocally planted along an environmental gradient in the Great Plains. Evolution 58: 1459-1471.

Falconer DS, Mackay TFC (1996). Introduction to Quantitative Genetics, 4th edn. Longman: England.

Fitter AH, Fitter RSR (2002). Rapid changes in flowering time in British plants. Science 296: 1689-1691.

Fry JD (2003). Detecting ecological tradeoffs using selection experiments. Ecology 84: 1672-1678.

Galloway LF (2005). Maternal effects provide phenotypic adaptation to local environmental conditions. New Phytol 166: $93-100$.

Galloway LF, Etterson JR (2005). Population differentiation and hybrid success in Campanula americana: geography and genome size. J Evol Biol 18: 81-89.

Galloway LF, Etterson JR (2007). Inbreeding depression in an autotetraploid herb: a three cohort field study. New Phytol 173: 383-392.

Galloway LF, Etterson JR, Hamrick JL (2003). Outcrossing rates and inbreeding depression in the herbaceous autotetraploid Campanula americana. Heredity 90: 308-315.

Geber MA, Griffen LR (2003). Inheritance and natural selection on functional traits. Int J Plant Sci 164 (3 Suppl): S21-S42.

Griffith TM, Watson MA (2005). Stress avoidance in a common annual: reproductive timing is important for local adaptation and geographic distribution. J Evol Biol 18: 1601-1612.

Haggerty BP (2006). Responses to Growing Season Length in the American Bellflower, Campanulastrum Americanum: Implications for Climate Change. M.S. thesis, Univeristy of Virginia, USA.

Hansen V, Totland O (2006). Pollinator visitation, pollen limitation, and selection on flower size through female function in contrasting habitats within a population of Campanula persicifolia. Can J Bot 84: 412-420.

Hauser TP, Weidema IR (2000). Extreme variation in flowering time between populations of Silene nutans. Hereditas 132: 95-101.

Houle D (1992). Comparing evolvability and variability of quantitative traits. Genetics 130: 195-204.

Kalisz S, Wardle GM (1994). Life history variation in Campanula americana (Campanulaceae): population differentiation. Am J Bot 81: 521-527.

Kelly CA (1992). Spatial and temporal variation in selection on correlated life-history traits and plant size in Chamaecrista fasciculata. Evolution 46: 1658-1673.

Kollmann J, Bañuelos MJ (2004). Latitudinal trends in growth and phenology of the invasive alien plant Impatiens glandulifera (Balsaminaceae). Divers Distrib 10: 77-385.

Maad J, Alexandersson R (2004). Variable selection in Platanthera bifolia (Orchidaceae): phenotypic selection differed between sex functions in a drought year. J Evol Biol 17: 642-650.

Masterson J (1994). Stomatal size in fossil plants: evidence for polyploidy in majority of angiosperms. Science 264: 421-424.

Mazer SJ, Schick CJ (1991). Constancy of population parameters for life-history and floral traits in Raphanus sativus L. II. Effects of planting density on phenotype and heritability estimates. Evolution 45: 1888-1907.

Olsson K, Agren J (2002). Latitudinal population differentiation in phenology, life history and flower morphology in the perennial herb Lythrum salicaria. J Evol Biol 15: 983-996.

O'Neil P (1997). Natural selection on genetically correlated phenological characters in Lythrum salicaria L. Lythraceae). Evolution 51: 267-274.

Otto SP, Whitton J (2000). Polyploid incidence and evolution. Annu Rev Genet 34: 401-437. 
Primack D, Imbres C, Primack RB, Miller-Rushing AJ, De Tredici P (2004). Herbarium specimens demonstrate earlier flowering times in response to warming in Boston. Am J Bot 91: 1260-1264.

Rathcke B, Lacey EP (1985). Phenological patterns of terrestrial plants. Annu Rev Ecol Syst 16: 179-214.

Réale D, McAdam AG, Boutin S (2003). Genetic and plastic responses of a northern mammal to climate change. Proc $R$ Soc Lond B Biol Sci 270: 591-596.

Roff DA (1997). Evolutionary Quantitative Genetics. Chapman \& Hall: New York.

Sarkissian T, Harder L (2001). Direct and indirect responses to selection on pollen size in Brassica rapa L. J Evol Biol 14: 456-468.
SAS Institute (2002). JMP-The Statistical Discovery Software, version 5.0. SAS Institute, Cary: NC, USA.

Soltis DE, Soltis PS (2003). Advances in the study of polyploidy since Plant Speciation. New Phytol 161: 173-191.

Van Dijk H, Boudry P, McCombie H, Vernet P (1997). Flowering time in wild beet (Beta vulgaris ssp maritima) along a latitudinal cline. J Ecol 18: 47-60.

Worley AC, Barrett SCH (2000). Evolution of floral display in Eichhornia paniculata (Pontederiaceae): direct and correlated responses to selection on flower size and number. Evolution 54: 1533-1545.

Wricke G, Weber WE (1986). Quantitative Genetics and Selection in Plant Breeding. Walter de Gruyter: Berlin. 